\title{
A Retrospective evaluation of hysterolaparoscopy as primary diagnostic tool for female infertility
}

\author{
Shehla Jamal, Mridula Sharma*, Kainat Masroor, Shravi Singh
}

Department of Obstetrics and Gynaecology, RMRI, Bareilly, Uttar Pradesh, India

Received: 08 November 2021

Revised: 07 December 2021

Accepted: 08 December 2021

\section{*Correspondence:}

Dr. Mridula Sharma,

E-mail: drmridu@gmail.com

Copyright: () the author(s), publisher and licensee Medip Academy. This is an open-access article distributed under the terms of the Creative Commons Attribution Non-Commercial License, which permits unrestricted non-commercial use, distribution, and reproduction in any medium, provided the original work is properly cited.

\begin{abstract}
Background: Infertility has been equally challenging and frustrating to the couple as well as physician. The causative etiology can have multitude of factors. Evaluation of underlying factors and formulating uniform diagnostic protocols is still a challenge for most of the infertility experts. This study was aimed to evaluate hysterolaparoscopy as primary diagnostic tool for female infertility.

Methods: This is a retrospective study conducted in the department of obstetrics and gynecology, SMS and R, Sharda University, Greater Noida, Uttar Pradesh. The data was collected from January2018 to December 2019. A total of 84 cases were studied. Data were entered into Epi-data version 3.1 and then exported to SPSS version 20 for cleaning and analysis. Chi-square test and logistic regression were done.

Results: Around $86.9 \%$ of the patients had abnormal findings. $13 \%$ of the patients had no abnormal laparoscopic findings, according to our inclusion criteria. One or the other findings were encountered in $96.4 \%$ of the cases. Only $3.5 \%$ of the patients had no discernible characteristics as per our inclusion protocol.

Conclusions: Irrespective of the investigations protocols used, hysterolaparoscopy finds its importance in most of the clinical settings. This investigative approach is professed as superior to hysterosalpingogram and Saline Infusion sonography when used alone. In the present study, we propose diagnostic hysterolaproscopy as first and one step approach, between days 8-11 of the cycle, as an effective diagnostic tool in cases of infertility.
\end{abstract}

Keywords: Hysterolaparoscopy, Infertility, Diagnostic tool

\section{INTRODUCTION}

The occurrence of infertility is about $10 \%-15 \%$ of reproductive age couples. ${ }^{1}$ WHO defines infertility as "a disease of the reproductive system defined by the failure to achieve a clinical pregnancy after 12 months or more of regular unprotected sexual intercourse." According to WHO overall prevalence of primary infertility in India is between 3.9 and $16.8 \% .^{2}$ when causative factors are analysed, sexually transmitted infections are amongst the leading cause, especially in developing countries which can lead to pelvic inflammatory disease (PID) and subsequent tubal damage. ${ }^{3}$ Hysterolaparoscopy has emerged as an indispensible tool in the evaluation of infertile patient. The endocervical canal, endometrial cavity, endometrium, tubal ostia, tubo-ovarian anatomy, peritoneal factors are visualized in a systematic fashion, and the results are objective. Operative hysterolaparoscopy further aids the management and leads to better treatment outcomes. Exhaustive literature suggests that hysterolaparoscopic investigation of the uterine cavity and external uterine surface along with adnexae improves fertility treatment outcomes. This paper aims at retrospectively evaluating $\mathrm{HL}$ as primary investigation approach for patients with infertility, in order to increase therapeutic efficacy offered to such couples. 
Aim

Aim of the current study was to diagnose the etiological factors of infertility in the couple attending the infertility clinic, OBG department, SMS and R using diagnostic hysterolaparoscopy and to analyse those etiological factors.

\section{METHODS}

This is a retrospective study conducted in the department of obstetrics and gynecology, SMS and R, Sharda University, Greater Noida, Uttar Pradesh. The data was collected from January 2018 to December 2019. All the cases were performed on day 8-11 of the menstrual cycle. Endometrial sampling was performed prior to DHL, to rule out endometrial TB and tissue was examined for histopathological evidence of infection or other lesions.

\section{Inclusion criteria}

Inclusion criteria for current study were; Primary/secondary infertility, thyroid disorders, hyperprolactinemia ruled out, AMH in normal range, male factor evaluated, endometrial evaluation to rule out tuberculosis by CBNAAT

\section{Exclusion criteria}

Exclusion criteria for current study were; tubal disease already evaluated by HSG, Active tuberculosis, endometritis as diagnosed by endometrial tissue evaluation.

\section{Procedure}

For doing hysteroscopy, patient's cervix was prepared using misoprostol 200 microgram vaginally one hour prior to the procedure. We used $5 \mathrm{~mm} 30$ degree telescope for hysteroscopy and used normal saline for distention of the cavity. All the findings were recorded in the imbedded video recorder. Hysteroscopy was done using no touch technique and vaginoscopy was performed prior to hysteroscopy in each patients. Endometrial abnormalities were recorded under following categories: structural abnormalities, endometrial abnormalities like paleness, stippling, polypoidal etc, cervical abnormalities as stenosed cervix, growth etc and laparoscopy was performed using pneumoperitonium creation by veress needle followed by trocar entry. We used 30 degree telescope for visualisation of pelvic and peritoneal structures. Results were obtained using percentage method.

\section{RESULTS}

A total of 84 cases were studied. Out of them, 69 were of primary infertility and rest were secondary infertility. Majority (45.2\%) were in 26-35 age group, followed by age group of $18-25(38 \%)$. More than 35 years age group constituted $16.6 \%$ of the cases. Maximum cases were of primary infertility (82.2\%) and majority (63.1\%) had infertility of more than one year (Table 1).

Table 1: Demography characteristics.

\begin{tabular}{|lll|}
\hline Characteristics & $\mathbf{N}$ & $\%$ \\
\hline Age (years) & & \\
\hline $18-25$ & 32 & 38 \\
\hline $26-35$ & 38 & 45.2 \\
\hline$>35$ & 14 & 16.6 \\
\hline Infertility & & \\
\hline Primary & 69 & 82.2 \\
\hline Secondary & 15 & 17.8 \\
\hline Duration (years) & & \\
\hline One & 31 & 36.9 \\
\hline$>1$ & 53 & 63.1 \\
\hline
\end{tabular}

Around $86.9 \%$ of the patients had abnormal findings, and $7.1 \%$ had unilateral tubal block, and $16.6 \%$ had bilateral tubal block. Endometriosis was found in $22.6 \%$ cases, filmsy adhesions were encountered in $7.1 \%$, whereas dense adhesions were present in $4.7 \%$ of the cases. Around $13 \%$ of the patients had no abnormal laparoscopic findings, according to our inclusion criteria (Table 2).

Table 2: laparoscopic findings.

\begin{tabular}{|lll|}
\hline Features & N & $\%$ \\
\hline Endometriosis & 19 & 22.6 \\
\hline Distorted anatomy & 9 & 10.7 \\
\hline Filmsy adhesion & 6 & 7.1 \\
\hline Dense adhesion & 4 & 4.7 \\
\hline Myoma & 9 & 10.7 \\
\hline Anomalies & 6 & 7.1 \\
\hline U/L blockade & 6 & 7.1 \\
\hline B/L blockade & 14 & 16.6 \\
\hline Normal & 11 & 13 \\
\hline
\end{tabular}

Adhesiolysis was performed in 10, tubal cannulation in 4, and lateral metroplasty in 7cases. On follow up, patients in whom tubal cannulation was performed, all conceived. One or the other findings were encountered in $96.4 \%$ of the cases. In hysteroscopy stippled endometrium suggestive of endometritis was found in $13 \%$ cases, pale endometrium was found in $21.4 \%$, whereas fluffy endometrium was found in $14.2 \%$ cases. Corneal puckering/Annular appearance was found in $7.1 \%$ cases. Only $3.5 \%$ of the patients had no discernible characteristics as per our inclusion protocol.

\section{DISCUSSION}

Hysterolaparoscopy (HL) is an extremely important tool for the evaluation of female infertility and is considered as the gold standard investigation for tubal patency. ${ }^{2} \mathrm{~A}$ detailed and thorough visualization of the uterine cavity, 
endometrium, tubal morphology and patency, uterine, ovarian, peritoneal and adnexal pathology can be performed in a single step. These pathology findings are often impossible to ascertain in our clinical examination and even on sonographic evaluation. Moreover, HL also provides the opportunity of therapeutic interventions to be offered in a single setting.

Table 3: Hysteroscopic findings.

\begin{tabular}{|lll|}
\hline Findings & N & $\%$ \\
\hline Myoma (SM) & 11 & 13 \\
\hline Polyps & 6 & 7.1 \\
\hline Malformation & 4 & 4.7 \\
\hline Ashermann's & 3 & 3.5 \\
\hline Stippled endometrium & 21 & 25 \\
\hline Pale endometrium & 18 & 21.4 \\
\hline Fluffy endometrium & 12 & 14.2 \\
\hline Annular/puckered cornuae & 6 & 7.1 \\
\hline Normal & 3 & 3.5 \\
\hline
\end{tabular}

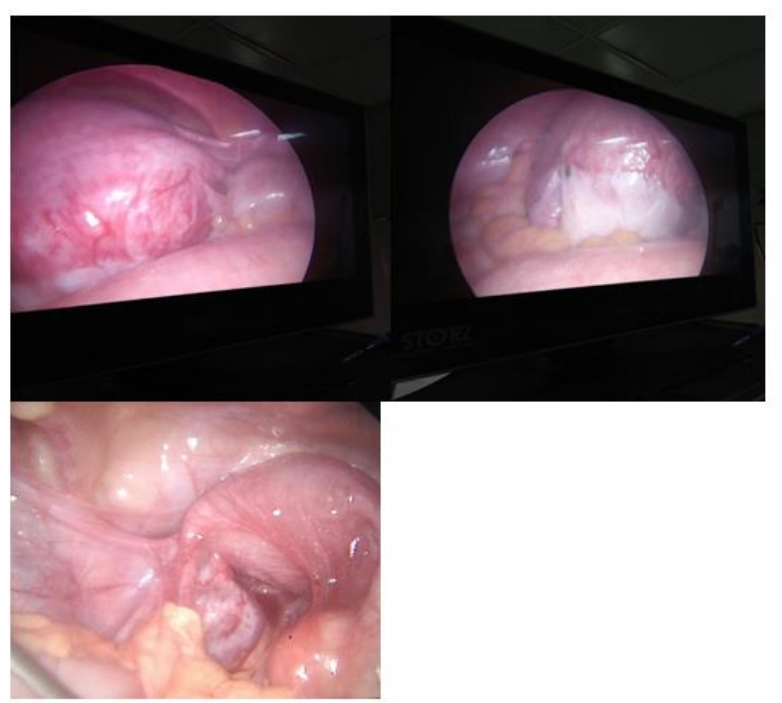

Figure 1: Dense adhesions.

\section{Laparoscopy}

Previously, some studies have shown that diagnostic laparoscopy did not reveal any pathology or only minimal and mild endometriosis in $40-70 \%$ of all cases, but in our study, no attributable laparoscopic factor was found only in $13 \%$ of the total. ${ }^{11}$ The difference obtained may be due to the fact that the patients were offered HL in the initial course of infertility evaluation in our set up. In a study done by Godinjak et al in which they performed simultaneous laparoscopy and hysteroscopy in 360 infertile cases and found tubal occlusion in $8 \%$, pelvic adhesion in $11 \%$, myomas $11 \%$, endometrial polyp $7 \%$, Asherman syndrome in $0.8 \%$, uterine anomalies in $5 \%$ cases. $^{3}$ In our analysis, on the contrary, endometriosis was the commonest finding in laparoscopy $(22.6 \%)$, but this finding is corroborating with the findings by other authors, in which they detected endometriosis as the major factor. ${ }^{4,5}$ It is estimated that around $30 \%-50 \%$ patients with endometriosis suffer from infertility, and laparoscopic investigation is the gold standard. ${ }^{6}$

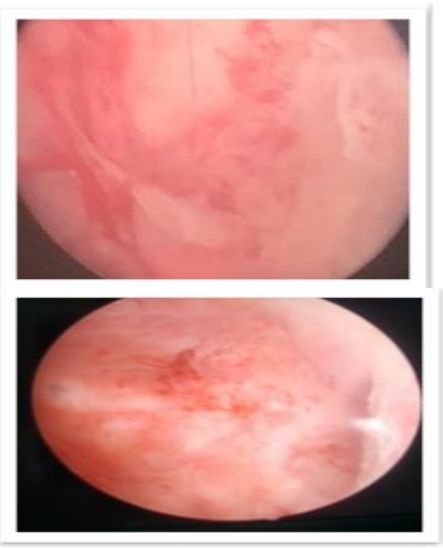

Figure 2: Stippled endometrium.

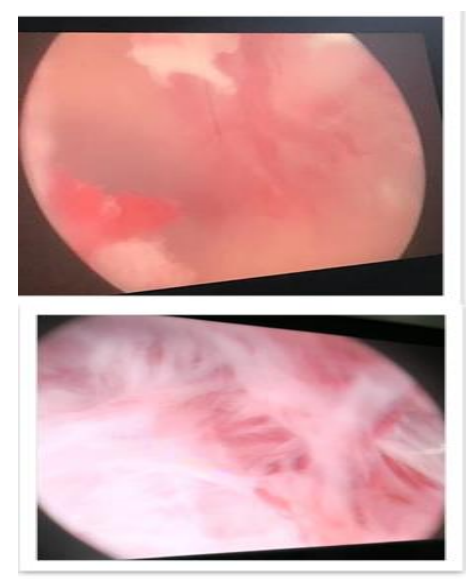

Figure 3: Fluffy endometrium.

\section{Hysteroscopy}

Pritts et al concluded that submucosal fibroids (International federation of gynecology and obstetrics (FIGO0 L0-L2) which cause distortion of the uterine cavity resulted in the decreased rates of clinical pregnancy, implantation, and ongoing pregnancy/live birth, as well as an increased rate of spontaneous miscarriage. ${ }^{7}$ In the analysis, the incidence of myomas on laparoscopy was $10.7 \%$. In the present retrospection, incidence of Ashermann's syndrome was $3.5 \%$. Asymptomatic endometrial polyps in women with infertility has been reported to range from $10 \%$ to $32 \% .8,9$ A prospective study of 224 infertile women on hysteroscopy showed a $50 \%$ pregnancy rate after polypectomy. ${ }^{10}$ In our study, the incidence of polyps was $7.1 \%$. in other studies incidence as close to $12 \%$ has been cited. ${ }^{11}$ In the present study, unhealthy endometrium exhibited various features such as stippling, patchy appearance, pale and fluffy (Figure 2-3). On further 
evaluation, the endometrium of such patients showed features of endometritis on histopathological examination.

\section{Tubal factors}

In the present analysis, incidence of bilateral tubal blockade was higher as compared to unilateral tubal blockade. This finding has been similar to the findings by other authors also. ${ }^{12}$ Pelvic inflammatory disease is a major risk factor for blocked tubes. Tubal factor infertility is the foremost reason of infertility among female patients, the majority of which is due to PID. ${ }^{13}$ Even subclinical PID is substantially associated with infertility and women with subclinical PID achieved $40 \%$ less pregnancies compared to women without the same. ${ }^{14}$

\section{CONCLUSION}

In our opinion, $\mathrm{HL}$ is a good initial diagnostic step, with 360 degree of evaluation of uterine, tubo-peritoneal and endometrial examination. At tertiary care centre it can well be incorporated in the initial evaluation protocol of infertile couples. However, retrospective nature of our study limits the validation of our result. We recommend more prospective studies, especially pertaining to finding out different endometrial features, so that further research generates more evidence. One big advantage of offering $\mathrm{HL}$ is delineating the exact etiological factor. In addition to this, surgical procedures like adhesiolysis, ovarian drilling, ovarian cystectomy, salpingostomy, myomectomy, polypectomy and release of uterine synechia can safely be done in a single setting. Such an approach should enhance the outcome in terms of achieving increased pregnancy and live birth rates.

\section{Funding: No funding sources}

Conflict of interest: None declared

Ethical approval: The study was approved by the Institutional Ethics Committee

\section{REFERENCES}

1. Boivin J, Bunting L, Collins JA, Nygren KG. International estimates of infertility prevalence and treatment-seeking: Potential need and demand for infertility medical care. Hum Reprod. 2007;22:150612.

2. Mol BW, Collins JA, Burrows EA, van der Veen F, Bossuyt PM. Comparison of hysterosalpingography and laparoscopy in predicting fertility outcome. Hum Reprod. 1999;14:1237-42.

3. Godinjak Z, Idrizbegovic E. Should diagnostic hysteroscopy be a routine procedure during diagnostic laparoscopy in infertile women? JBMS. 8;2008:4447.

4. Puri S, Jain D. Laparohysterocopy in female infertility: A diagnostic cum therapeutic tool in Indian setting. Int J App Basic Med Res. 2015;5(1): 46-8.

5. Tsuji I, Ami K. Miyazaki A. Huzinami N. Benefit of diagnostic laparoscopy for patients with unexplained infertility and normal hysterosalpingography findings. Tohoku J Exp Med. 2009; 219:39-42.

6. Counsellor VS. Endometriosis. A clinical and surgical review. Am J Obstet Gynecol. 1938;36:877.

7. Hinckley MD, Milki AA. 1000 office-based hysteroscopies prior to in vitro fertilization: Feasibility and findings. JSLS. 2004;8:103-7.

8. Shalev J, Meizner I, Bar-Hava I, Dicker D, Mashiach $\mathrm{R}$, Ben-Rafael Z. Predictive value of transvaginal sonography performed before routine diagnostic hysteroscopy for evaluation of infertility. Fertil Steril. 2000;73:412-7.

9. Shokeir TA, Shalan HM, EI-Shafei MM. Significance of endometrial polyps detected hysteroscopically in eumenorrheic infertile women. J Obstet Gynaecol Res. 2004;30:84-9.

10. Bosteels J, Van Herendael B, Weyers S, D'Hooghe T. Th e position of diagnostic laparoscopy in current fertility practice. Hum Reprod Update. 2007;13:47785.

11. Study of Role of Combined Diagnostic Hysteroscopy and Laparoscopy in Evaluating Factors for Infertility. JMSCR. 2018;11(1):19-23.

12. Chanu SM, Rudra Pal GS, Panda S, Santa Singh AS. Diagnostic Hysterolaparoscopy for Evaluation of Infertility: Our Experience in a Tertiary Care Hospital. J Hum Reprod Sci. 2018;11(1):19-23.

13. Assisted Reproductive Technology Success Rates: National Summary and Fertility Clinic Reports. Available at: https://www.cdc.gov/art/artdata/index. html. Accessed on 20 September 2021.

14. Wiesenfeld HC, Hillier SL, Meyn LA, Amortegui AJ, Sweet RL. Subclinical pelvic inflammatory disease and infertility. Obstet Gynecol. 2012;120:37-43.

Cite this article as: Jamal S, Sharma M, Masroor K, Singh S. A Retrospective evaluation of hysterolaparoscopy as primary diagnostic tool for female infertility. Int J Reprod Contracept Obstet Gynecol 2022:11:91-4. 